\title{
Assessment in Music in the Australian Context: The AiM Project
}

\author{
Don Lebler, Queensland Conservatorium Griffith University, Australia
}

\begin{abstract}
This paper reports on the outcomes of the Assessment in Music (AiM) project, which was funded by the Australian Government's Office for Learning and Teaching (OLT). The project commenced in 2011 and will conclude in 2015, and its principal focus is the alignment between assessment and a range of mandated learning outcomes in the Australian context. Among other activities, the project team has mapped all core assessment tasks in Bachelor degree programs at the lead institution to the Creative and Performing Arts Threshold Learning Outcome statements (CAPA TLOs), the Graduate Attributes (GAs) of the lead institution's host university, and the Australian Qualifications Framework (AQF) Program Learning Outcomes (Australian Qualifications Framework Council, 2013).

As consensus moderation has been adopted at its host university to enhance the validity and reliability of assessment practices, this process has been used in the project as a means of developing a shared understanding of assessment standards at participating institutions, as well as other aspects of the project's activities. This paper reports on the findings of extensive mapping exercises and the results of consensus moderation processes with teaching staff. It will also describe a process that has been implemented to develop shared understandings of the standards applied to the assessment of musical performance between institutions.
\end{abstract}

\section{Introduction}

The Assessment in Music (AiM) project was funded by the Australian Government's Office for Learning and Teaching and it explores the nature of academic standards as they are applied in higher music education across Australia. The assessment of learning outcomes for music degrees provides a focus for the project, which draws on the experiences of staff and students across a range of programs and musical sub-disciplines-jazz, musical theatre, music technology, popular and classical music - to identify best-practice assessment processes.

The project's main interest was to investigate how well the achievement of the Threshold Learning Outcome Statements developed for the Creative and Performing Arts (CAPA TLOs) (Holmes \& Fountain, 2010) can be measured by existing assessment standards and practices in higher music education in Australia. In this paper, program means a program of study for which a qualification is awarded, and courses are those 
individual subjects or units that constitute a program of study. Though no program-level assessment is conducted in the Australian context, all degree programs are now required to publish learning outcomes that must be assessed within the courses that students have undertaken: the accumulated assessments are regarded as a proxy for program-level assessment. Assessment tasks for 350 core undergraduate assessment items were mapped to the CAPA TLOs, the host University's Graduate Attributes (GAs), and subsequently to the published program learning outcomes (PLOs).

Traditionally, assessment in conservatoire settings is conducted largely according to the protocols of individual institutions and without external validation, and this is particularly true for the assessment of musical performance, so the new requirement to demonstrate achievement of PLOs represents a major shift for the Australian higher music education sector. The project found that a variety of assessment tasks assessed students' achievement of the Bachelor degree learning outcomes and AQF Bachelor Degree learning outcomes, thereby satisfying the requirements of the AQF.

\section{Context}

An extensive study of Australian assessment practices in music at the Bachelor level (Monkhouse, 2007) found the development of performance ability to be the primary goal of higher music education and the main focus of its assessment practices. However, broader skills as represented by the CAPA TLOs are now viewed as important learning outcomes for students preparing for careers in the Arts. A number of studies at the lead institution (see for example Lebler, 2008a; Carey \& Lebler, 2012; Harrison, Lebler, Carey, Hitchcock, \& O'Bryan, 2013) indicate that a major component of assessment at this site involves solo and ensemble performance, and although present in some instances, alternative forms of assessment such as peer, self and group assessment remain underutilised in this location.

The Creative and Performing Arts Threshold Learning Outcomes for bachelor degrees are:

1 Demonstrate skills and knowledge of the practices, languages, forms, materials, technologies and techniques in the Creative and Performing Arts discipline.

2 Develop, research and evaluate ideas, concepts and processes through creative, critical and reflective thinking and practice.

3 Apply relevant skills and knowledge to produce and realise works, artefacts and forms of creative expression.

4 Interpret, communicate and present ideas, problems and arguments in modes suited to a range of audiences.

5 Work independently and collaboratively in the Creative and Performing Arts Discipline in response to project demands.

6 Recognise and reflect on social, cultural and ethical issues, and apply local and international perspectives to practice in the Creative and Performing Arts Discipline. 


\section{Methodology}

Drawing on the work of Sadler $(2007,2009,2011,2015)$, the lead institution has focussed on its assessment practices as part of its host university's current emphasis on assessment, which employs consensus moderation to develop a common understanding of standards and thereby ensure consistency of marking (Griffith University, 2014). In this process, academics individually consider a range of student responses to a particular assessment task and share their views on the standard of achievement demonstrated by these responses. Through this process, assessors develop a shared understanding of the standards that apply to student achievement and are then able to work independently using these shared understandings. The consensus moderation approach was also used in the AiM project to review the alignment between learning and assessment and national threshold learning outcomes in tertiary music programs. Project team members worked independently and then collaboratively, in an iterative fashion, resulting in shared views on how the various learning outcomes related to each other, leading to a shared understanding of how assessment activities aligned with various learning outcomes.

As a means of working towards a broader inter-institutional consensus on standards of student achievement, a similar process has been be undertaken at the project's partner institutions. The sharing of a variety of standards as exhibited in audio and video recordings of performance examinations will assist in ensuring comparability of the grades awarded as measures of student achievement and provides a model for moving towards sector-wide consensus.

\section{Description of Process}

Following an extensive literature review and a survey of current assessment practices in higher music education in Australia, the team collated the learning objectives for each of the 350 core course undergraduate assessment items and mapped the relationship between these assessment tasks and the nineteen Graduate Attributes of the host university and the CAPA TLOs. The analysis indicated that all the Graduate Attributes (and by extension, CAPA TLOs) were assessed repeatedly. Given the extensive research already undertaken into the Bachelor of Popular Music (BPM) (for example, see Lebler \& Carey, 2008; Lebler, 2006, 2007, 2008a, 2008b, 2010, 2012, 2015; Lebler, Burt-Perkins, \& Carey, 2009), this instance is used as an example in this paper, but similar findings apply to the other degree programs.

In the BPM program, Graduate Attributes were each assessed more than 20 times in semester 2, 2011 in the 34 assessment activities analysed, and more than 18 times in semester 2, 2012 over 23 assessment items in the courses that all students are required to undertake; elective courses were not included in the analysis. This demonstrated that the required learning outcomes are being thoroughly assessed in this program. In order to verify the claims made for the assessment of learning outcomes in the course profiles, a form of consensus moderation was undertaken whereby the academics responsible for the design of course profiles consulted with another academic to ensure they were in 
agreement as to the claims made in each course. This process is now mandated for the entire University.

The team has also conducted focus group sessions with teachers and students at the host institution to discuss their perceptions of the relationship and relevance of the six CAPA TLOs to current assessment practices. All participants agreed that current methods of assessment successfully addressed the CAPA TLOs in an ongoing, developmental manner. Teachers expressed some doubts about what level of achievement demonstrated a threshold standard, and they questioned the extent to which the CAPA TLOS represented a professional industry standard, which remained an important reference point for most teachers when assessing student performances, particularly at the point of graduation. While external criteria were acknowledged as important, teachers often made judgments according to a student's demonstrated ability and according to each student's unique combination of strengths and weaknesses, and then related these to the required learning outcomes (Cain, 2015). This process is described by D. Royce Sadler as backwards assessment (Sadler, 2015). In general, teachers agreed that gross disagreement in panel assessment almost never occurred, and that when significant differences were noted, consensus was always achieved through discussion (Cain, 2015).

An inter-institutional instance of consensus moderation was conducted between the three partner institutions. The process involved selecting recordings of student performances that were shared using Dropbox. After each participant had reached a conclusion as to the standard demonstrated in the recording, the academics from each institution met to discuss their views, reaching a local consensus. The three groups of academics then met on line using Skype video conferencing and a representative of each institution shared that institution's views, leading to an inter-institutional dialogue resulting in an agreed understanding of the standards demonstrated. This process provides a model for the development of inter-institutional consensus and it can be achieved at almost no cost other than the time of the academics involved and the very small cost of Skype Premium.

\section{Mapping the AQF Learning Outcomes}

While the initial objective of the AiM project was to investigate the degree to which assessment standards and practices at the host institution align with the CAPA TLOs, the extent to which these assessment standards and practices satisfy the requirements of the Australian Qualifications Framework (AQF) (Australian Qualifications Framework Council, 2013) was also investigated.

A Bachelor Degree is identified as Level Seven of the 10 AQF levels. Graduates at this level are described as possessing "a broad and coherent body of knowledge as a basis for independent lifelong learning", "cognitive skills to review critically, analyse, consolidate and synthesise knowledge", and the ability to apply knowledge and skills "with initiative and judgement in planning, problem solving and decision making in professional practice" (Australian Qualifications Framework, 2013, p. 13).

The process involved mapping the program level outcomes for the Bachelor of

Music, Bachelor of Popular Music and Bachelor of Musical Theatre programs at QCGU to 
the AQF learning outcomes, the Institutional GAs and the CAPA TLOs. This was intended to determine if all graduates have an opportunity to demonstrate all Level Seven AQF outcomes through the assessment tasks in these programs. Specific assessment items were identified in which the AQF learning outcomes are demonstrated and assessed. The results showed that in each of these three programs, there are several examples of assessment tasks which satisfy all AQF learning outcomes, all program level outcomes and all CAPA TLOs. Therefore, the lead institution can demonstrate with confidence that these three Bachelor degree programs satisfy the accreditation requirements of the AQF.

In the Bachelor of Music program, several courses satisfied the AQF learning outcomes through a combination of assessment tasks. These included the most advanced core performance courses and a vast range of electives. Assessment tasks which satisfied AQF learning outcomes include: artistic performances, reflective journals, research essays, written tests, in-class presentations, critical reviews, group presentations, written examinations, portfolios, analysis tasks, proformas and project reports.

\section{Conclusions and Future Directions}

The processes described in this paper have provided the AiM project team with an understanding of the ways assessment processes at the lead institution relate to the AQF and CAPA learning outcomes for Bachelor degree programs. Results indicate that the process of consensus moderation has been helpful in developing consistency of marking and a common understanding of standards at the host institution. The mapping process used provides a possible template for use in other institutions and may indeed apply in the evaluation of assessment practices in other Arts areas.

Continuing activities for the AiM project include additional focus group sessions with staff and students at the lead institution to further inform the team of the impact of revised assessment. A repository based on examples of work and assessment procedures currently in place at the lead institution and its two partner institutions has been developed and access to these resources is currently available by application through the project website (assessmentinmusic.com.au). The resources and information on the AiM web site will assist in the development of a shared inter-institutional understanding of the standards applied in the assessment of higher education music.

\section{References}

Australian Qualifications Framework Council. (2013). Australian Qualifications Framework ( $2^{\text {nd }}$ ed.). Retrieved from http://www.aqf.edu.au/wpcontent/uploads/2013/05/AQF-2nd-Edition-January-2013.pdf

Cain, M. (2015). Participants' Perceptions of fair and valid assessment in tertiary music education. In D. Lebler, G. Carey, \& S. Harrison (Eds.), Assessment in music education: From policy to practice. London, U.K.: Springer.

Carey, G., \& Lebler, D. (2012). Reforming a Bachelor of Music program: A case study. International Journal of Music Education, 30(4), 309-326. doi:10.1177/0255761412459160 
Griffith University. (2014). Assessment policy. Brisbane: Griffith University. Retrieved from http:// policies.griffith.edu.au/pdf/Assessment Policy.pdf.

Harrison, S. D., Lebler, D., Carey, G., Hitchcock, M., \& O'Bryan, J. (2013). Making music or gaining grades? Assessment practices in tertiary music ensembles. British Journal of Music Education, 30(1), 27-42. doi:10.1017/S0265051712000253

Holmes, J., \& Fountain, W. (2010). Creative and performing arts learning and teaching academic standards statement. Sydney: Australian Learning and Teaching Council.

Lebler, D. (2006). The masterless studio: an autonomous education community. Journal of Learning Design, 1(3), 41-50.

Lebler, D. (2007). Student-as-master? Reflections on a learning innovation in popular music pedagogy. International Journal of Music Education, 25(3), 205-221. doi:10.1177/0255761407083575

Lebler, D. (2008a). Perspectives on assessment in the learning of music. In D. Bennett \& M. Hannan (Eds.), Inside, outside, downside up: Conservatoire training and musicians' work (pp. 181-193). Perth, Australia: Black Swan Press.

Lebler, D. (2008b). Popular music pedagogy: peer-learning in practice. Music Education Research, 10(2), 193-213. doi:10.1080/14613800802079056

Lebler, D. (2010, July). Informal learning in formal learning: Web 2 to the rescue. Paper presented at the Musician in Creative and Educational Spaces of the 21st Century [electronic resource]. Proceedings from the International Society for Music Education (ISME) 18th International seminar of the Commission for the Education of the Professional Musician, Shanghai Conservatory of Music.

Lebler, D. (2012). Technology and students' musicking: Enhancing the learning experience. Theory into Practice, 51(3), 204-211. doi:10.1080/00405841.2012.690302

Lebler, D. (2015). The BoPMAT: Bachelor of Music popular music program. In D. Lebler, G. Carey, \& S. Harrison (Eds.), Assessment in music education: From policy to practice. London, U.K.: Springer.

Lebler, D., Burt-Perkins, R., \& Carey, G. (2009). What the students bring: Examining the attributes of commencing conservatoire students International Journal of Music Education: Research, 27(3), 232-249. doi:10.1177/0255761409335950

Lebler, D., \& Carey, G. (2008). Prior learning of conservatoire students: A popular music perspective. Paper presented at the 17 th International Seminar of the International Society for Music Education Commission for the Education of the Professional Musician Commission, Spilamberto, Italy. Retreived from http://www.members.isme.org/ceprom/ceprom-proceedings-2008-9.html

Monkhouse, H. (2007). Performance assessment of classical woodwind instruments in the Australian Tertiary Sector. University of Tasmania, Faculty of Arts Teaching Fellowship Report. Retrieved from http://www.altcexchange.edu.au/system/files/2007 TF report.pdf

Sadler, D. R. (2007). Perils in the meticulous specification of goals and assessment criteria. Assessment in education: Principles, policy E practice, 14(3), 387-392. doi:10.1080/09695940701592097 
Sadler, D. R. (2009). Indeterminacy in the use of preset criteria for assessment and grading. Assessment \& Evaluation in Higher Education, 34(2), 159-179. doi:10.1080/02602930801956059

Sadler, D. R. (2011). Academic freedom, achievement standards and professional identity. Quality in Higher Education, 17(1), 85-100. doi:10.1080/13538322.2011.554639

Sadler, D. R. (2015). Backwards assessment explanations: Implications for teaching and assessment practice. In D. Lebler, G. Carey \& S. Harrison (Eds.), Assessment in music education: From policy to practice. London, U.K.: Springer. 